\title{
AVALIAÇÃO DAS CAUSAS DAS SUBSTITUIÇÕES DE RESTAURAÇÕES NAS DISCIPLINAS DE DENTÍSTICA II E CLÍNICA INTEGRADA DO CURSO DE ODONTOLOGIA DA UNIPAR - CAMPUS UMUARAMA
}

\author{
EVALUATION OF RESTORATIONS SUBSTITUTION CAUSES IN \\ PRACTICAL ACTIVITIES OF RESTORATIVE DENTISTRY II \\ AND INTEGRATED CLINICAL DISCIPLINES FROM UNIPAR \\ DENTISTRY COURSE - CAMPUS UMUARAMA
}

\author{
Patrícia Dubinski ${ }^{1}$, Sueli de Almeida Cardoso², Márcio Grama Hoeppner² \\ 1 Autor para contato: Universidade Paranaense - UNIPAR, Curso de Odontologia, \\ Umuarama, PR, Brasil; (44) 99562775/ Fax: (44) 3626-2081; e-mail: patidubi@bol.com.br \\ 2 Universidade Paranaense - UNIPAR, Departamento de Odontologia, Umuarama, PR \\ Recebido para publicação em 07/10/2004 \\ Aceito para publicação em 13/06/2005
}

\begin{abstract}
RESUMO
O objetivo deste trabalho foi avaliar as causas das substituições de restaurações dentais dos pacientes atendidos nas disciplinas de Dentística II e Clínica Integrada, do Curso de Odontologia da UNIPAR - Umuarama. A pesquisa foi realizada durante 12 meses, por alunos do $3^{\circ}$. e $4^{\circ}$. anos orientados por professores das referidas disciplinas. Foram avaliadas 352 restaurações substituídas, sendo 201 de amálgama de prata e 151 de resina composta. Os principais motivos que levaram à troca das restaurações foram: reincidência de cárie para amálgama de prata e manchamento de interface para as restaurações de resina composta. Observou-se que um grande número de restaurações confeccionadas com material adesivo apresentou cárie no decorrer de sua vida útil. 58 restaurações de resina composta foram trocadas em um intervalo de uso de 1 a 5 anos. Enquanto 81 restaurações de amálgama foram substituídas após tempo de uso entre 5 e 10 anos. Assim, concluiu-se que para a resina composta, erro na técnica restauradora, mais sensível, e na indicação clínica, podem comprometer sua longevidade. A busca pela estética e o uso de parâmentros subjetivos adotados para o diagnóstico fazem com que o ciclo restaurador se repita entre alunos e profissionais.
\end{abstract}

Palavras-chave: restaurações, causas, substituições 


\begin{abstract}
The aim of this study was to evaluate replacement of restorations causes from patients that had been treated by Restorative Dentistry II and Integrated Clinical disciplines from UNIPAR Dentistry Course-Campus Umuarama. The research was carried through during 12 months by students of $3^{\text {th }}$ and $4^{\text {th }}$ series, guided by professors of the disciplines. At the end of data collection, 352 restorations had been substituted, between them 201 amalgam restorations and 151 composite resin restorations. The main reasons that conducted to decision of exchange the amalgam had been relapsed caries and spotted interface of composite resin. It was observed that a great number of restorations made with adhesive material showed caries during its useful life. A greater number of composite resin restorations had been substituted in the interval from 1 to 5 years. 81 amalgam restorations had been substituted between 5 and 10 years of use. By these data, it was possible to conclude that composite resin is more sensible to the technique, it has its useful lifetime reduced compared to amalgam and when it is not adequately indicated, its longevity can reduce still more. The search for esthetic and the subjective parameters used for diagnosis, make with the restoring cycle repeats between students and professionals.
\end{abstract}

Key words: restorations, causes, substitution

\section{Introdução}

A prática de uma Odontologia respaldada apenas na utilização de materiais e técnicas resultou em uma forma mecânica de tratamento de dentes comprometidos por cárie. Assim, por anos, a realização de preparos cavitários e o preenchimento com materiais restauradores de última geração foram vistos como uma forma adequada de tratamento, sendo portanto as restaurações consideradas permanentes. Em vez de tratar da etiologia da doença, os esforços se concentravam na promoção da cura apenas através da reposição da porção dental perdida, o que levou a acreditar que o sucesso do tratamento restaurador estaria na dependência das técnicas e materiais empregados.

Entretanto, inúmeros trabalhos relatam que não apenas o número de restaurações vem aumentando, mas também a quantidade de restaurações substituídas (Baratieri et al., 2001; Fontana et al,. 1994). Portanto, equivocados estão os que acreditam que um dente restaurado está livre de novas intervenções, bem como os que julgam que o tratamento mecânico da cárie através da confecção de restaurações se mostra sufici- ente para promover saúde. Mais do que habilidade, promover saúde bucal consiste em mudanças de comportamento, tanto por parte dos pacientes como, principalmente, dos cirurgiões-dentistas (Pereira et al., 2003). Do contrário, restaurações continuarão sendo substituídas por outras maiores e mais complexas, comprometendo a resistência do remanescente dental (Elderton, 1997). Diagnosticar o risco à doença e lesões de cárie em estágio clínico inicial, bem como educar o paciente, representam medidas elementares à elaboração e ao sucesso de qualquer tratamento (Pereira et al., 2003). Da mesma forma, avaliar quão necessária se mostra a substituição das restaurações já existentes.

As restaurações dentárias são artifícios usados para prolongar a vida dos dentes, contudo não os mantêm isentos da possibilidade de recidiva da doença (Charbeneau et al., 1978; Bindslev e Mjor., 1993; Vilella et al., 1991; Phillips,R.W., 1993; Pimenta e Pimenta, 1996; Baratieri et al., 2001). Isso deixa claro que ao invés da dentística restauradora tradicional, a atenção deve ser voltada ao entendimento da etiologia da doença cárie, para assim permitir a atuação dentro 
de princípios preventivos e conservadores, e portanto, promotores de saúde (Pereira et al., 2003).

Assim, frente à suspeita de que a longevidade das restaurações pode ser menor que o real potencial de que são capazes, mesmo com toda a evolução técnica, a realização deste trabalho teve por objetivo avaliar as causas das substituições das restaurações dentais dos pacientes atendidos nas disciplinas de Dentística II e Clínica Integrada do Curso de Odontologia da Universidade Paranaense - Campus Umuarama.

\section{Material e método}

Restaurações de resina composta e amálgama de prata, indicadas para substituição nas atividades clínicas das disciplinas de Dentística II ( $3^{\mathrm{a}}$ série) e Clínica Integrada ( $4^{\mathrm{a}}$ série), foram avaliadas clínica e radiograficamente durante o período de 12 meses. Assim, foram obtidas informações através dos pacientes, referentes à longevidade aproximada da restauração, bem como informações coletadas pelo próprio avaliador sobre o material restaurador a ser substituído e características clínicas da restauração, tais como: presença de corrosão superficial, manchamento, desadaptação ou excesso marginal, fratura da restauração ou do remanescente dental, além de presença de cárie recorrente e material restaurador a ser utilizado na substituição. As coletas dos dados foram realizadas por alunos avaliadores previamente treinados, os quais foram supervisionados pelos professores responsáveis. Ao final do período estipulado, as informações foram tabuladas e o percentual para cada um dos itens estudados foi calculado.

\section{Resultados}

Em 12 meses de pesquisa, 352 restaurações substituídas foram avaliadas. Sendo 201 de amálgama de prata e 151 de resina composta. Entre as restaurações de amálgama substituídas, 60 (29,85\%) foram realizadas por reincidência de cárie, 45 (22,38\%) por contorno e anatomia deficientes, 45 (22,38\%) por degradação marginal, 44 (21,9 \%) por fratura (região de istmo ou corpo da restauração), 3 (1,5\%) por razões estéticas, 3 (1,5\%) por corrosão e 1 (0,49 \%) por outras razões não especificadas (Gráfico 1 ). Das 151 restaurações de resina composta substituídas, 72 $(47,7 \%)$ foram por manchamento na interface, 46 (30,46\%) por manchamento do corpo da restauração, 28 (18,54\%) por reincidência de cárie, 4 (2,64\%) por contorno e anatomia deficientes e $1(0,66 \%)$ por outras razões não especificadas (Gráfico 2). Em relação ao material restaurador utilizado para substituição, das 201 restaurações de amálgama de prata 88 foram substituídas pelo mesmo material e 113 por resina composta (Gráfico 3). Por sua vez, das 151 restaurações de resina composta substituídas, 3 utilizaram amálgama de prata e em 148 foi utilizado o mesmo material restaurador, resina composta (Gráfico 4). Com relação à idade das restaurações substituídas, 5 restaurações de amálgama tinham menos de um ano, 43 restaurações tinham entre 1 e 5 anos, 81 tinham entre 5 e 10 anos e 71 tinham mais de dez anos de uso (Gráfico 5). Entre as restaurações de resina composta, 14 restaurações tinham menos de um ano, 58 tinham entre 1 e 5 anos, 39 entre 5 e 10 anos e 40 restaurações mais de dez anos de uso (Gráfico 6). 


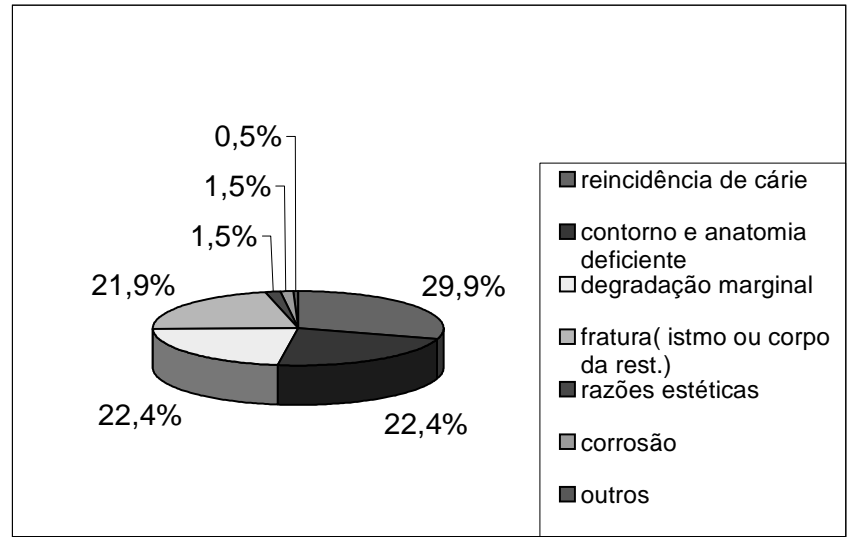

Gráfico 1 - Motivos para substituição de 201 restaurações de amálgama.

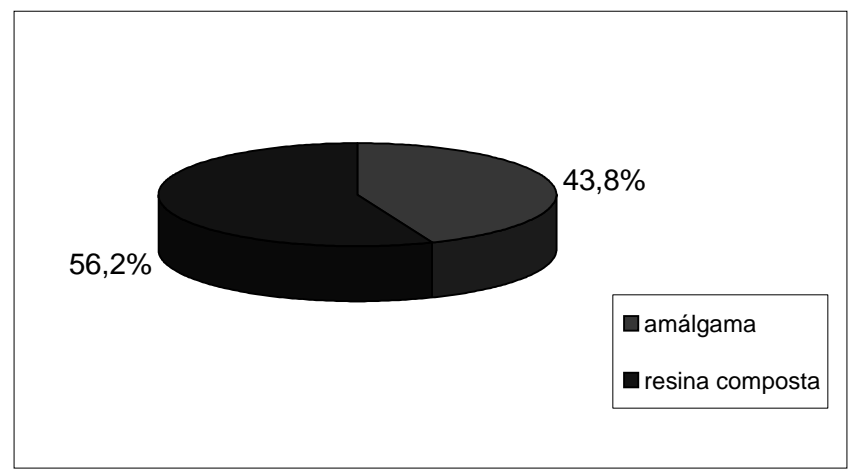

Gráfico 3 - Materiais restauradores utilizados para substituir 201 restaurações de amálgama de prata.

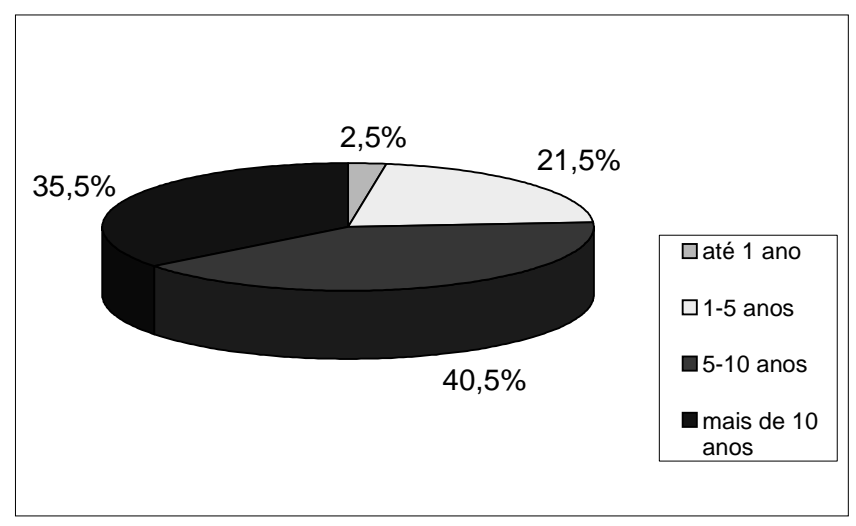

Gráfico 5 - Tempo de vida útil de 201 restaurações de amálgama.

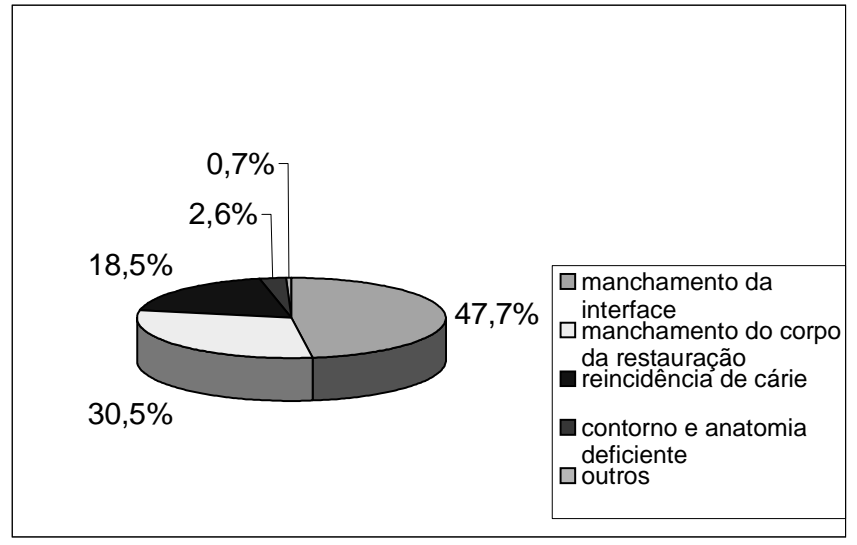

Gráfico 2 - Motivos para substituição de 151 restaurações de resina composta.

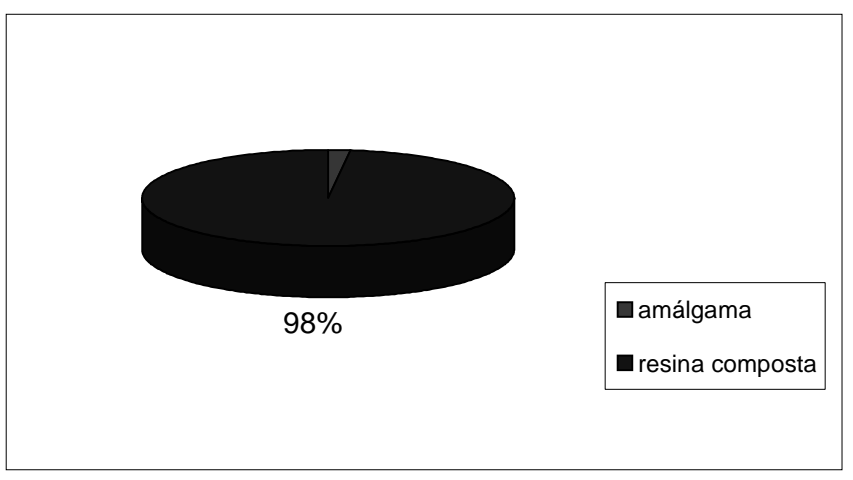

Gráfico 4 - Materiais restauradores utilizados para substituir 151 restaurações de resina composta.

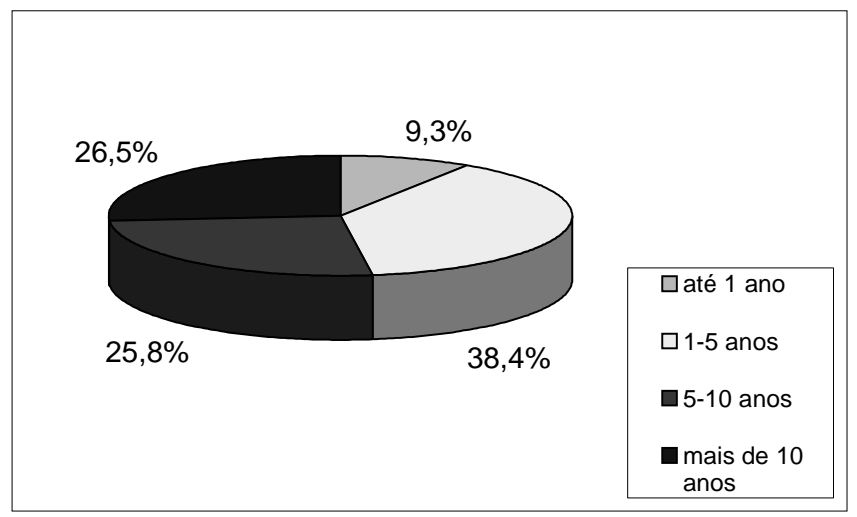

Gráfico 6 - Tempo de vida útil de 151 restaurações de resina composta 


\section{Discussão}

Em virtude dos avanços científicos e da probabilidade de associar conhecimentos, já é possível entender a dinâmica do processo carioso, estabelecendo a real necessidade de tratamento. Sabe-se que a progressão da lesão difere de indivíduo para indivíduo e tem relação direta com o uso de fluoretos, capacidade tampão salivar, dieta e retenção de placa. Com isso, torna-se imprescindível o diagnóstico precoce, tendo em vista que a cárie ainda sem cavitação pode ser revertida dispensando a necessidade de procedimentos curativos (Pereira et al., 2003).

Apesar dos procedimentos curativos constituírem uma etapa fundamental no tratamento da cárie e recuperarem a função e a estética das estruturas dentais, sabe-se que uma vez confeccionados, mais tarde, por inúmeras razões, podem exigir substituições (Baratieri et al., 2001; Fontana et al., 1994).

Segundo autores (Baratieri et al., 2001; Pimenta e Pimenta, 1996), as restaurações são substituídas principalmente pela recorrência da doença cárie e pelas falhas técnicas. Assim, o ciclo restaurador repetitivo tem sido mantido por décadas (Elderton, 1976; Elderton, 1997; Baratieri et al., 2001) uma vez que a qualidade das restaurações depende de critérios subjetivos adotados por cada profissional.

A evolução dos materiais odontológicos não diminuiu o número de substituições, ainda responsáveis por grande parte dos procedimentos diários realizados por profissionais (Villela et al., 1991; Baratieri et al., 2001).

Os dados obtidos pela presente pesquisa corroboram os da literatura consultada (Charbeneau et al., 1978); Bindslev e Mjor., 1993; Villela et al., 1991; Phillips, 1993; Pimenta e Pimenta, 1996; Baratieri et al., 2001), mostrando que a cárie recorrente é a principal razão para substituição de restaurações em amálgama, seguido pela anatomia deficiente e degradação marginal. Das 201 restaurações de amálgama substituídas, 29,85\% foram trocadas por apresentarem recidiva de cárie. Estes dados somam-se às pesquisas anteriores e mostram um comportamento retilíneo do amálgama no decorrer dos anos. Fato este que não ocorre em relação às resinas compostas, entre as quais foi encontrado um percentual de falhas relativas a manchamento de interface que veio a superar todas as outras, correspondendo a $47,7 \%$ de uma amostra de 151 restaurações avaliadas.

Para Bindslev e Mjor (1993), 50-60\% das restaurações de amálgama de prata são substituídas devido à cárie recorrente, sendo isso detectado somente pelo fato da sonda exploradora prender nas margens das restaurações. Os autores afirmaram que $40 \%$ das trocas são feitas por integridade duvidosa associada ou não à cárie, e que $40 \%$ das substituições ocorreram com mais de 10 anos. Dentre as 352 restaurações substituídas avaliadas neste trabalho, a recidiva de cárie foi responsável pelo percentual de 30\%, correspondendo a 60 restaurações de amálgama de prata e 28 de material estético e 31,25\% do total de restaurações substituídas tinham mais de dez anos de uso, correspondendo a 71 restaurações de amálgama e 40 restaurações de resina composta.

Quando se avalia manchamento de interface em restaurações de resina composta, clinicamente fica difícil diagnosticar se houve apenas a falha do sistema adesivo e desadaptação da resina composta, ou se já existe um processo inicial de lesão cariosa a nível microscópico. Partindo desse ponto de vista é provável que muitas restaurações tenham sido substituídas com caráter preventivo, na tentativa de evitar maiores danos aos tecidos dentais. Fontana et al. (1994) afirmaram que a recidiva de cárie está associada à infiltração marginal e é dependente do tempo e da correta indicação do material restaurador, associada a falhas de técnica.

Ainda com relação aos motivos para substituição, 45 restaurações de amálgama de prata foram trocadas por degradação marginal e 72 restaurações de resina composta foram trocadas por manchamento da interface. Isso comprova as observações feitas por Fontana et al. (1994), que no quesito infiltração marginal, a resina composta supera o amálgama de prata, exigindo um período mais curto para sua substituição.

O grande percentual de substituições feitas por manchamento da interface das restaurações de resina composta, em dentes restaurados com técnicas adesivas, faz com que se concorde com Busato et al. (1997) quando afirmaram que a contração de polimerização pode levar a fendas marginais e conseqüentemente microinfiltração, manchas e recidiva de 
cárie, aumentando a sensibilidade pulpar.

Das 151 restaurações de resina composta, 46 foram substituídas por manchamento do corpo da restauração. Esse manchamento pode ser decorrente da polimerização inadequada do material (Groth et al., 1996) ou da pigmentação superficial (Veronezi, 2001). O desgaste oclusal e a rugosidade superficial, mesmo em restaurações polidas, foram comumente observados após períodos de 2 a 3 anos (Mondelli et al., 1990), o que favorece a pigmentação superficial.

Entre as restaurações de amálgama analisadas neste estudo, 45 foram substituídas por falha de contorno ou anatomia deficiente. Segundo Elderton (1976), falta de contorno, pobre adaptação e modelo cavitário são as principais causas das falhas das restaurações.

Das 201 restaurações de amálgama de prata, 41 (21,9\%) foram substituídas por fratura de istmo ou corpo da restauração. Em estudo clínico realizado por Healey e Phillips (1949) foi demonstrado que as causas de falhas das restaurações de amálgama eram devidas a: 56\% preparo cavitário incorreto, 40\% manipulação inadequada do material e $4 \%$ por razões periodontais, complicações pulpares e outras. Estes dados comprovam os achados de Mondelli et al (1990) que apontaram 25\% das falhas relacionadas à fratura da restauração. Para Villela et al. (1991), a interrelação entre as falhas, começando por um preparo incorreto, pode culminar com a fratura da restauração. Entretanto, nem todas as restaurações que apresentam defeitos necessitam realmente de troca, podendo apenas receber recontorno e repolimento (Bálsamo et al., 1996; Baratieri et al., 2001; Amore et al., 2001). A troca, mesmo que por estética, desgasta e enfraquece o dente e não deixa o paciente livre da possibilidade de recorrência da cárie.

Fazendo referência ao tempo de vida útil das restaurações avaliadas nesta pesquisa, apenas 5 restaurações de amálgama de prata foram substituídas com menos de um ano de uso clínico. Esses dados podem estar relacionados com a afirmação de que a degradação marginal do amálgama tem seu pico de crescimento nos primeiros seis meses de vida, mantendo-se mais estável no decorrer dos anos (Busato et al., 1986).

Ainda de acordo com Busato et al.(1986), o tempo de 2 anos é insuficiente para que uma restaura- ção de amálgama de prata ou resina composta se apresente insatisfatória, desde que bem confeccionada e indicada. Neste trabalho observou-se que 58 das 151 restaurações de resina composta e 43 das 201 restaurações de amálgama de prata foram substituídas com tempo de uso entre 1 e 5 anos. Para Mondelli et al. (1990) mesmo uma restauração de amálgama feita adequadamente, respeitando os princípios da técnica, após 4-5 anos apresenta tendência à fratura das margens devido aos esforços mastigatórios.

Com tempo de vida útil entre 5 e 10 anos, 81 restaurações de amálgama de prata e 39 restaurações de resina composta foram trocadas. Segundo Markley (1951) “uma restauração de amálgama sempre parece pior do que realmente é... “ o que é confirmado por Phillips (1993), que observou que pelo menos 90\% das restaurações de amálgama apresentavam-se satisfatórias após 5 anos de uso. E mesmo não apresentando cárie, a restauração que não está com boa aparência é trocada na tentativa de prevenir o aumento da deterioração. Isso só seria minimizado se fosse possível o diagnóstico microscópico de cada fenda marginal.

Com relação ao material selecionado para confecção das novas restaurações, das 201 restaurações de amálgama de prata substituídas, 88 foram restauradas com amálgama de prata e 113 com resina composta. Para Nunes (1988) e Mondelli et al, (1990), as ações clínicas do profissional têm implicações diretas no sucesso das restaurações.

Das 151 restaurações com material estético substituídas, 3 foram restauradas com amálgama de prata e 148 com resina composta, confirmando o aumento na busca pela estética, tanto dos futuros profissionais quanto dos pacientes. De acordo com Christensen (1998), é preciso que os pacientes estejam conscientes das vantagens e desvantagens desse material sedutor que é a resina composta.

Cabe ao profissional dar maior ênfase à prevenção e aos critérios de avaliação, pois existem falhas clinicamente aceitáveis em uma restauração, e se essa não puder ser reparada, os fatores que levaram a tal diagnóstico merecem atenção especial a fim de serem corrigidos, evitando procedimentos clínicos desnecessários. 


\section{Conclusão}

A partir dos resultados obtidos, pôde-se concluir que:

1- Considerando o tipo de material restaurador substituído, a reincidência de cárie representou o principal fator para a substituição das restaurações de amálgama de prata. Enquanto que para as restaurações de resina composta substituídas, a estética foi o principal motivo (manchamento de interface e manchamento de corpo da restauração).

2- Considerando os materiais restauradores utilizados na substituição das 201 restaurações de amálgama, 56,2\% dos preparos foram restaurados com resina composta e 43,8\% usaram o amálgama de prata. Já para as 151 restaurações de resina composta, em $98 \%$ dos preparos o material de escolha foi a resina composta e apenas $2 \%$ utilizaram o amálgama de prata.

3- Com relação ao tempo de vida útil das restaurações de amálgama substituídas, 25\% tinham menos de 5 anos de uso, enquanto que $75 \%$ tinham mais que 5 anos de uso. O tempo de vida útil das 151 restaurações de resina composta substituídas se mostrou reduzido em relação ao do amálgama de prata, uma vez que $48 \%$ apresentavam menos de 5 anos de uso e $58 \%$ mais de 5 anos de uso.

4- A qualidade e indicação para a substituição das restaurações estão diretamente relacionadas a parâmetros subjetivos e, muitas vezes, de difícil definição entre os alunos operadores, avaliadores e professores.

5- O tratamento restaurador das lesões de cárie ou substituição das restaurações já existentes, quando associado a condutas preventivas, contribui para a longevidade da restauração e do remanescente dental.

\section{Agradecimentos}

Aos alunos avaliadores da $4^{\mathrm{a}}$ série (2004) do Curso de Odontologia da UNIPAR - Umuarama: João Fagan Junior, João Vitor Pinheiro Barranco e Darlei Luiz Taglian.

À professora Renata Corrêa Pascoto, da disci- plina de Dentística Restauradora da UEM.

\section{REFERÊNCIAS}

1. AMORE, R.; ANIDO, A.A.; PAGANI, C. Restaurações extensas de amálgama. J. Bras. Clin. Odontol Int, Curitiba, v.5, n30, p. 513-518, nov/dez, 2001.

2. BÁLSAMO, M.; CESAR, A.F. Reparo de margem de amálgama apresentando valamento marginal utilizando resina tipo flow. Revista Odontológica de Santo Amaro, v.4 n.2, p.6668, jul/dez, 1996.

3. BARATIERI, L.N. JUNIOR, S.M; ANDRADA, M.A.C.; VIEIRA, L.C.C.; RITTER, AV.; CARDOSO, A.C. Odontologia restauradora. Fundamentos e Possibilidades. São Paulo: Santos, 2001. 735p.

4. BINDSLEV; MJOR. Dentística Operatória Moderna, trad. Sylvio Monteiro Jr. 2. ed, São Paulo: Santos, 1993. 306p.

5. BUSATO, A L.S.; JUNIOR, J.G. Resina Composta em dentes posteriores. Estudo comparativo entre restaurações de amálgama e resina composta em dentes posteriores. Rev Gaúcha Odont, v.34, n.5 p.420-424, set/out, 1986.

6. BUSATO, AL.S; ROMANO, AR; TORRIANI, D.D; CRUZEIRO, M.T.R. Dentística: Restaurações em dentes posteriores. Porto Alegre: Artes Médicas, 1996. 301p.

7. BUSATO, AL.S; BARBOSA, A.N.; BUENO, M; BALDISSERA, R. Dentística: Restaurações em dentes anteriores. Porto Alegre: Artes Médicas, 1997. 481p.

8. CHARBENEAU, G.T.; CARTWRIGHT, C.B.; CONSTOCK, F.W.; KAHLER, F.W.; SNYDER, D.T.; DENNISON, J.B.; MARGESON, R.D. Princípios e Prática de Dentística Operatória, trad. Dioracy Fonterrada Vieira. Rio de Janeiro: Guanabara Koogan, 1978. 442p.

9. CHRISTENSEN, G.J. Durabilidade versus Estética na dentística restauradora. JADA-Brasil, v.1, p.63-64, out/1998.

10. CROLL, T.P. Utilização de ionômero de vidro compósito na reobturação de cavidades cl.I em amálgama. Quintessência, v.1, n.4, p.203-209, 1990.

11. ELDERTON, R.J. The causes of failure of restaurations: a literature review. Journal of Dentistry, v.4, n.6, p. 257-262, 1976.

12. ELDERTON, R.J. Ciclo restaurador repetitivo. In:KRIGER,L. ABOPREV- Promoção de Saúde Bucal. São Paulo: Artes Médicas, 1997, p.195-200, cap.10.

13. FARAH, J.W.; POWERS, J.M. Desempenho clínico após 5 anos da resina Z100-3M. The Dental Advisor, ed. em português, v.5, n.7, p.1-4, ago/1998. 
14. FONTANA, U.F.; DINELLI, W.; NORDI, P.P.; MILORI, S.A. Avaliação clínica em resina composta para dentes posteriores. Revista Paulista de Odontologia, Ano XVI, n.3, p.6-11, mai/ jun, 1994.

15. GABRIELLI, F.; ROLFSEN, R.L.; DINELLI, W.; FONTANA, U.F. Estudo clínico das falhas das restaurações de amálgama. Revista Fac. Farm. Odont. Araraquara, v.6, p.165-171, 1972.

16. GROTH, E.B.; EDUARDO, C.P.; GONÇALVES, J.A. Avaliação da intensidade de emissão de luz de aparelhos fotoativadores e sua influência nas resinas compostas. Rev Gaúcha Odont., v.44, n.3, p.143-145, maio/jun,1996.

17. JURCUIKONIS, S.; CENTOLA, A.L.B.; NASCIMENTO, T.N.; TURBINO, M.L. Critérios para prevenção da troca das restaurações de amálgama. Rev Gaúcha Odont, v.43, n.5, p.292294, set/out, 1955.

18. KRAMER, P.F. Promoção de Saúde Bucal em Odontopediatria: diagnóstico, prevenção e tratamento da cárie oclusal. Porto Alegre: Artes Médicas, 1997.141p.

19. MONDELLI, J.; ISHIKIRIAMA, A.; JUNIOR, J.G.; NAVARRO, M.F.L. Dentística Operatória, 4a . ed. São Paulo: Savie, 1990. 254p.

20. NUNES, O.B.C. Avaliação clínica das restaurações de amálgama: revisão da literatura. Odontologia Moderna, v.5, n.6, p.22-23, 1988.

21. PEREIRA, A.C.; GONCALVES, N.C.L.AV.; MIALHE, F.L. Odontologia em Saúde Coletiva: Planejando ações e promovendo saúde. Porto Alegre: Artemed, 2003. p.440.

22. PHILLIPS, R.W. Skinner- Materiais Dentários. 9. ed. Guanabara \& Koogan, 1993. 328p.

23. PIMENTA, L.A. F.; PIMENTA I.C. Quando e por que reparar as restaurações de amálgama. Revista Brasileira de Odontologia, v.53, n.5, p.32-34, 1996.

24. SMALES, R. J.; WEBSTER, D.A.; LEPPARD, P.I.; DAWSONT, A.S. Prediction of amalgam restoration longevity. J. Dent, v.19, p.18-23, 1991.

25. ROULET, J.F.; NOVACK, M.J. Criteria of substituting amalgam with composite resins. International Dental Journal, Berlin Germany. V.41, p.195-205, 1991.

26. VERONEZI, M.C. et al. The influence of the quality of the light-curing uniys on composite resins staining. In: DOMINGUES, L.A.; SAKAMOTO, F.F.O.; TOMA, M.H. Selantes superficiais influenciam no manchamento das resinas? Revista APCD, v.55, n.5, p. 321-325, set/out. 2001.

27. VILLELA, C.L.; ARAÚJO, M,A.J.; VILLELA, G.L. Substituição das restaurações de amálgama. Rev Gaúcha Odont, v.39, n.4, p.303-305, jul/ago, 1991 